\title{
PENERAPAN METODE FUZZY MAMDANI UNTUK MEMPREDIKSI ANGKA PENJUALAN TOKEN BERDASARKAN PERSEDIAAN DAN JUMLAH PERMINTAAN PADA PT. PLN (Persero) PADANG BERBASIS WEB
}

\author{
Devia Kartika, Rini Sovia, Hoka Muhgrah Sandawa, \\ Universitas Putra Indonesia "YPTK", Padang \\ devia.kartika11@gmail.com, rinisovia4@gmail.com, muhgrah@gmail.com
}

\begin{abstract}
ABSTRAK
Listrik merupakan kebutuhan mendasar untuk berbagai aktifitas manusia, yang kemudian digunakan untuk beragam fungsi kedepannya. Dalam mekanisme sekarang ini PT. PLN menerapkan sistem listrik pintar meteran prabayar (token). Dalam menentukan jumlah penjualan token ini dikembangkan dengan menerapkan metode Fuzzy Mamdani. Tujuan yang dicapai adalah untuk memprediksi angka penjualan token berdasarkan data persediaan dan jumlah permintaan. Pada proses fuzzy, input dibagi menjadi 2 variabel yaitu persediaan dan permintaan. Himpunan fuzzy untuk output penjualan token yaitu rendah, sedang, dan tinggi. Pengembangan sistem ini dibuat berbasis web menggunakan bahasa pemrograman PHP (Hypertext Prepocessor) dan Database MySQL. Pada penelitian ini, penulis menggunakan UML (Unified Modeling Language) dalam perancangan program.
\end{abstract}

Kata Kunci: Penjualan, Persediaan, Permintaan, PHP (Hypertext Prepocessor), Metode Fuzzy Mamdani.

\section{PENDAHULUAN}

Listrik saat ini menjadi kebutuhan mendasar untuk berbagai aktifitas manusia, yang kemudian digunakan untuk beragam fungsi kedepannya. Listrik menjadikan manusia ketergantungan akan keberadaannya, tidak dapat dipungkiri bahwa listrik merupakan tenaga yang dibutuhkan manusia dalam segala hal yang mendukung aktifitas manusia. Suatu perusahaan besar PT. PLN memberikan pelayanan sebagai upaya pasti dalam memberikan pelayanan yang maksimal untuk kepentingan dan kemajuan bangsa.

Salah satu cara yang bisa digunakan dalam memprediksi jumlah produksi meteran prabayar (token) adalah penerapan logika fuzzy, karena terdapat beberapa data yang bisa digunakan dalam melakukan perhitungan guna mendapatkan prediksi jumlah produksi meteran prabayar (token). Didalam perhitungan logika fuzzy terdapat beberapa metode, yaitu metode tsukamoto, metode mamdani, dan metode sugeno. Setiap metode tersebut memiliki cara dan hasil perhitungan yang berbeda. Dalam kasus ini, masalah yang timbul adalah bagaimana cara menerapkan metode fuzzy mamdani untuk memprediksi angka produksi meteran prabayar (token) berdasarkan data persediaan dan jumlah permintaan.

\section{LANDASAN TEORI}

\section{Rekayasa Perangkat Lunak (RPL)}

Perangkat lunak (software) adalah program komputer yang terasosiasi dengan dokumentasi perangkat lunak seperti dokumentasi kebutuhan, model desain dan cara penggunaan (user manual). Sebuah program komputer tanpa terasosiasi dengan dokumentasinya maka belum dapat dikatakan perangkat lunak (software). Sebuah perangkat lunak juga sering disebut dengan sistem perangkat lunak. Sistem berarti kumpulan komponen yang saling terkait satu sama lain dan mempunyai satu 
UPI YPTK Jurnal KomTekInfo Vol. 5, No. 1, Juni 2018, Hal. 81-95 ISSN :2356-0010 | eISSN :2502-8758 Copyright@2018 by LPPM UPI YPTK Padang

tujuan yang ingin dicapai. User atau pemakai perangkat lunak adalah orang yang memiliki kepentingan untuk memakai atau menggunakan perangkat lunak untuk memudahkan pekerjaannya

\section{Unified Modeling Languange (UML)}

Pada perkembangan teknologi perangkat lunak, diperlukan adanya bahasa yang digunakan untuk memodelkan perangkat lunak yang akan dibuat dan perlu adanya standarisasi agar orang di berbagai Negara dapat mengerti pemodelan perangkat lunak. Banyak orang telah membuat bahasa pemodelan pembangunan perangkat lunak sesuai dengan teknologi pemprograman yang berkembang pada saat itu, misalnya yang sempat berkembang dan digunakan oleh banyak pihak adalah Data Flow Diagram (DFD) untuk memodelkan perangkat lunak yang meggunakan pemrograman prosedural atau struktural, kemudian juga ada State Transition Diagram (STD) yang digunakan untuk memodelkan sistem real time (waktu nyata) (Rosa A.S. dan M. Shalahuddin,2013).

\section{Diagram-diagram UML}

Diagram $U M L$ yang dipakai dalam perancangan sistem pakar ini ada 7 diagram yaitu :

\section{Use Case Diagram} dibuat.

Diagram use case merupakan pemodelan untuk kelakuan (behavior) sistem informasi yang akan

\section{Class Diagram}

Class Diagram menggambarkan struktur dari sistem dari segi pendefenisian kelas-kelas yang akan dibuat untuk membangun sistem. Kelas memiliki apa yang disebut atribut dan metode atau operasi. Atribut merupakan variabel-variabel yang dimiliki oleh suatu kelas, dan operasi atau metode adalah fungsi yang dimiliki oleh suatu kelas.

\section{Sequence Diagram}

Diagram sekuen menggambarkan kelakuan objek pada use case dengan medeskripsikan waktu hidup objek dan massege yang dikirimkan dan diterima antar objek.

\section{Activity Diagram}

Activity Diagram menggambarkan berbagai aliran kerja atau aktifitas dari sebuah sistem atau proses bisnis atau menu yang ada pada perangkat lunak (Rosa A.S. dan M. Shalahuddin, 2013).

\section{State Machine Diagram}

Stetachart diagram atau dalam bahasa Indonesia disebut diagram mesin status atau sering juga disebut diagram status digunakan untuk menggambarkan perubahan status atau transisi status dari sebuah mesin atau sistem atau objek.

\section{Deployment Diagram}

Deployment Diagram menunjukkan konfigurasi komponen dalam proses eksekusi aplikasi

\section{Konsep Fuzzy Logic}

Logika fuzzy diperkenalkan oleh Prof. Lotfi Astor Zadeh pada tahun 1962. Logika fuzzy adalah metodologi sistem control pemecahan masalah, yang cocok untuk diimplementasikan pada sistem, mulai dari sistem yang sederhana, sistem kecil, embedded system, jaringan PC, multi channel atau workstation berbasis akuisisi data, dan sistem control (Anggia Dasa Putri dan Effendi, 2017).

\section{Himpunan Fuzzy}

Suatu pengembangan lebih lanjut tentang konsep himpunan dalam matematika. Pada himpunan tegas (crisp), nilai keanggotaan dalam suatu himpunan $A(\mu A(\chi))$ memiliki dua kemungkinan (Ami Hilda Agustin, dkk, 2016), yaitu : 
1. Satu (1) yang berarti bahwa suatu item menjadi anggota dalam suatu himpunan.

2. Nol (0) yang berarti bahwa suatu item tidak menjadi anggota dalam suatu himpunan.

Ada beberapa hal yang menjadi dasar dalam memahami fuzzy logic antara lain (Rahmaddeni, 2014) :

1. Variabel fuzzy, yaitu variabel yang akan dibahas dalam suatu sistem fuzzy .

2. Himpunan fuzzy, yaitu suatu kelompok yang mewakili suatu keadaan tertentu dalam suatu variabel fuzzy. Himpunan fuzzy memiliki 2 atribut yaitu :

a. Linguistik

b. Numeris

3. Semesta pembicaraan, yaitu seluruh nilai yang diizinkan untuk dioperasikan dalam suatu variabel fuzzy .

4. Domain himpunan fuzzy, yaitu seluruh nilai yang diizinkan dalam semesta pembicaraan dan boleh dioperasikan dalam suatu himpunan fuzzy.

\section{Fungsi Keanggotaan}

Fungsi keanggotaan adalah suatu kurva yang menunjukkan pemetaan titik-titik input data kedalam nilai keanggotaannya (sering juga disebut dengan derajat keanggotaan) yang memiliki interval 0 dan 1 . Salah satu cara untuk mendapatkan nilai keanggotaan adalah dengan melalui pendekatan fungsi.

\section{Sistem Fuzzy}

Sebuah sistem fuzzy adalah kemampuannya dalam proses penalaran secara bahasa sehingga dalam perancanganya tidak memerlukan persamaan matematik yang rumit (Anggia Dasa Putri dan Effendi, 2017).

\section{Metode Mamdani}

Metode mamdani sering dikenal sebagai metode max-min. Metode ini diperkenalkan oleh Ebrahim Mamdani pada tahun 1975. Untuk mendapatkan output diperlukan 4 tahapan, antara lain (Edy Victor Haryanto, 2015) :

1. Pembetukan himpunan fuzzy. Pada proses fuzzifikasi langkah yang pertama adalah menentukan variabel fuzzy dan himpunan fuzzy nya.

2. Aplikasi fungsi implikasi pada metode mamdani. Fungsi implikasi yang digunakan adalah $M I N$ dan MAX.

3. Komposisi aturan (rule). Tidak seperti penalaran monoton, apabila sistem terdiri dari beberapa aturan, maka inferensi diperoleh dari kumpulan antar aturan (rule).

4. Penegasan (defuzzy fikasi). Input dari proses defuzzy fikasi adalah suatu himpunan fuzzy yang diperoleh dari komposisi aturan-aturan fuzzy, sedangkan output yang dihasilkan merupakan suatu bilangan pada domain himpunan fuzzy tersebut.

\section{Keunggulan Metode Mamdani}

Menurut (Alfa Saleh, 2015) menerapkan metode fuzzy mamdani untuk melihat sejauh mana metode ini mampu memprediksi tingkat kebisingan lalu lintas. Dimana dalam memprediksi tingkat kebisingan lalu lintas pada penelitian ini agaknya telah digunakan untuk memprediksi peluang kejadian hujan dengan memanfaatkan data musim hujan, musim pancaroba dan musim kemarau.

\section{Web}

Web adalah sekumpulan halaman informasi yang disediakan melalui jalur internet sehingga bisa diakses diseluruh dunia selama terkoneksi dengan jaringan internet. Web merupakan sebuah komponen yang terdiri dari teks, gambar, suara animasi sehingga menjadi media informasi yang menarik untuk dikunjungi oleh orang lain. (Eka Praja Mandala, 2015). 
UPI YPTK Jurnal KomTekInfo Vol. 5, No. 1, Juni 2018, Hal. 81-95 ISSN :2356-0010 | eISSN :2502-8758 Copyright@2018 by LPPM UPI YPTK Padang

\section{HTML}

HTML adalah singkatan dari Hypertext Text Markup Languange. HTML merupakan bahasa yang digunakan untuk mendefinisikan sejumlah bagian seri sebuah dokumen web dalam bentuk tag, sehingga browser dapat mengetahui bagaimana menampilkan dokumen web tersebut yang mencakup link, text, gambar dan media-media lainnya seperti video atau audio (Eka Praja Mandala, 2015). Cascading Style Sheets (CSS) adalah aturan untuk megendalikan beberapa komponen dalam sebuah web sehingga akan lebih terstruktur dan seragam. CSS bukan merupakan bahasa pemprograman (Eka Praja Mandala, 2015).

\section{Bahasa Pemprograman Web}

PHP merupakan bahasa pemprograman script yang membuat dokumen HTML secara on the fly yang dieksekusi di server web, dokumen HTML yang dihasilkan dari suatu aplikasi bukan dokumen HTML yang dibuat dengan menggunakan editor teks atau editor HTML, dikenal juga sebagai bahasa pemprograman server side. PHP merupakan singkatan dari "Hypertext Preprocessor", merupakan bahasa utama script server side yang disisipkan pada HTML yang dijalankan di server, dan juga bisa digunakan untuk membuat aplikasi desktop (Betha Sidik, 2017).

\section{Konsep Database}

Secara umum, database berati koleksi data yang saling terkait. Secara praktis, basis data dapat dianggap sebagai suatu penyusunan data yang terstruktur yang disimpan dalam media pengingat (harddisk) yang tujuannya adalah agar data tersebut dapat diakses dengan mudah dan cepat. (Abdul Kadir, 2008). MySQL merupakan software yang tergolong sebagai DBMS (database management system) yang bersifat open source. Open source menyatakan bahwa software ini dilengkapi dengan source code (kode yang dipakai untuk membuat MySQL), selain tentu saja bentuk executable-nya atau kode yang dapat dijalankan secara lansung dalam sistem operasi, dan bisa diperoleh dengan cara mendownload secara gratis.

SQL

SQL adalah kependekan dari structured query language, dalam bahasa inggris SQL biasa dibaca sebagai SEQUEL atau ES-KYU-EL. Bahasa ini merupakan standar yang digunakan untuk mengakses database relasional. Standar SQL mula-mula didefiniskan oleh ISO (International Standards Organization) dan

\section{METODOLOGI PENELITIAN}

Agar penelitian ini berjalan dengan teratur, maka diperlukan sebuah kerangka penelitian. Berikut ini adalah kerangka penelitian yang dibuat :

\begin{tabular}{|c|}
\hline Indentifikasi Masalah \\
\hline$\downarrow$ \\
\hline Pengumpulan Data \\
\hline$\downarrow$ \\
\hline Analisa Data \\
\hline \\
\hline Perancangan Sistem \\
\hline$\downarrow$ \\
\hline Implementasi Sistem \\
\hline$\downarrow$ \\
\hline Pengujian Sistem
\end{tabular}


UPI YPTK Jurnal KomTekInfo Vol. 5, No. 1, Juni 2018, Hal. 81-95 ISSN :2356-0010 | eISSN :2502-8758

Copyright@2018 by LPPM UPI YPTK Padang

\section{Identifikasi Masalah}

Dalam tahap ini berisi latar belakang, ruang lingkup penelitian dan manfaat penulisan, tujuan umum perusahaan, sejarah perusahaan, visi dan misi, struktur organisasi, beserta deskripsi tugas masing-masing bagian dalam perusahaan.

\section{Pengumpulan Data}

Penelitian dilakukan dengan memproses data-data yang telah didapatkan oleh peneliti. Pengambilan data dilakukan dari tanggal 8 Oktober 2017 sampai dengan selesai.

\section{Tempat Penelitian}

Objek penelitian ini dilakukan pada perusahaan yang bernama PT. PLN Rayon Indarung yang berlokasi di Padang.

\section{Metode Penelitian}

Adapun metode penelitian yang dilakukan sebagai berikut :

a. Penelitian lapangan

Pada penelitian lapangan ini dilakukan wawancara dengan pegawai, untuk menganalisis masalah, serta memperoleh informasi yang dibutuhkan.

b. Riset Perpustakaan

Riset perpustakaan ini dilakukan dengan cara membaca, membahas, meringkas dan membuat kesimpulan dari buku-buku fuzzy logic, dan programing yang berkaitan dengan analisis dan perancangan data mining untuk mendapatkan bahan-bahan yang secara ilmiah dapat dijadikan landasan dalam menyusun penelitian ini .

c. Penelitian Laboratorium

Pada tahap ini melakukan peracangan pengelolahan data yang berhubungan dengan data perusahaan untuk menghasilkan informasi yang valid.

\section{Analisa}

Setelah data berhasil didapatkan, maka langkah selanjutnya adalah melalukan analisa terhadap data tersebut. Analisa data merupakan suatu usaha untuk mengkaji dan mengolah data yang telah didapatkan sehingga diperoleh suatu kesimpulan yang bermanfaat sesuai dengan tujuan penelitiaan. Metode analisis yang digunakan dalam penelitian fuzzy logic ini menggunakan metode analisa mamdani yang sering disebut metode MAX-MIN. Metode ini menggunakan sistem penalaran yang menyerupai instusi manusia (Anggia Dasa Putri dan Effendi, 2017). Analisa sistem juga dibutuhkan agar penulis dapat mendeskripsikan alur kerja sistem berdasarkan kebutuhan penggunanya. Dengan adanya analisa sistem diharapkan dapat menciptakan suasana user friendly terhadap sistem yang akan dibangun.

\section{Perancangan Sistem}

Setelah melakukan analisa terhadap data dan sistem, penulis juga melakukan perancangan terhadap sistem yang akan dibangun berdasarkan analisa sistem yang telah dilakukan.

\section{Perancangan Model}

Tahapan perancangan bertujuan untuk membuat penelitian dirancang sesuai dengan tujuannya, sehingga tidak melenceng dari tujuan penelitian. Akan dilakukannya proses pengumpulan data-data yang akan dilakukan untuk mendukung perancangan sistem sebagai objek penelitian. Perancangan akan menggunakan UML sebagai model rancangan agar terorganisasi dan terstruktur dengan rancangan.
1. Use Case Diagram
2. Class diagram
3. State diagram
4. Activity Diagram
5. Sequence Diagram

\section{Perancangan Interface}

Pada tahap ini dilakukan perancangan terhadap sistem yang akan dibangun dengan membuat tampilan interface yang sesuai dengan kebutuhan. Adapun dalam perancangan interface ini penulis mendeskripsikan konsep aplikasi yang akan dirancang sebagai acuan atau desain awal pada 
UPI YPTK Jurnal KomTekInfo Vol. 5, No. 1, Juni 2018, Hal. 81-95 ISSN :2356-0010 | eISSN :2502-8758 Copyright@2018 by LPPM UPI YPTK Padang

perancangan aplikasi fuzzy logic dengan metode mamdani. Desain yang dirancang berupa suatu web dengan 1 (satu) aktor yaitu kepala gudang. Dimana terdapat beberapa bagian didalamnya yaitu sebagia berikut :

1. Home sebagai halaman beranda depan pada aplikasi yang akan dirancang nantinya.

2. Aplikasi fuzzy, sebagai media kalkulasi jumlah produksi yang akan diminta.

3. Laporan produksi, sebagai informasi penyimpanan laporan permintaan.

4. Indentitas kepala gudang, sebagai tambahan profil kepala gudang atau manajer pada PT. PLN

Rayon Indarung.

\section{Pengujian Sistem}

Pengujian aplikasi pada sistem ini merupakan pengujian yang dilakukan dengan memasukan rumus logika fuzzy logic dengan metode mamdani didalam sebuah sistem aplikasi berbasis web agar aplikasi yang akan dirancang menjadi lebih efektif dan efisien dan mudah digunakan oleh kepala gudang pada PT. PLN Rayon Indarung untuk memprediksi angka permintaan selanjutnya.

\section{Pengujian Interface}

Pengujian interface yaitu pengujian terhadap desain aplikasi fuzzy logic yang akan diimplementasikan kedalam sebuah aplikasi web. Pengujian kecocokan warna, tampilan utama, dan semua yang akan dirancang kedalam sebuah aplikasi web nantinya.

\section{HASIL DAN PEMBAHASAN}

\section{Analisa Data}

Tahap analisa data merupakan tahap yang paling penting dalam penggembangan sebuah sistem, karena pada tahap ini nantinya dilakukan evaluasi indentifikasi terhadap masalah yang ada, rancangan sistem dan langkah-langkah dibutuhkan untuk perancangan yang diingikan sampai pada analisa yang diharapkan.

Analisa data didapatkan setelah melakukan pengamatan langsung di objek penelitian PT. PLN Rayon Indarung Padang yang berada di kecamatan penggambiran, kota Padang. Variabel-variabel data yang di dapatkan ialah data jumlah penjualan (pemasangan), persediaan dan jumlah permintaan barang. Data yang didapatkan terhitung dari bulan September 2016 sampai bulan September 2017 yang dapat dilihat dari tabel berikut ini:

Tabel.1 Data Permintaan

\begin{tabular}{|l|l|l|l|l|}
\hline No & Bulan & Permintaan & Persediaan & Penjualan \\
\hline 1 & Oktober & 504 & 376 & 349 \\
\hline 2 & November & 900 & 531 & 369 \\
\hline 3 & Desember & 502 & 1062 & 362 \\
\hline 4 & Januari & 14 & 1202 & 398 \\
\hline 5 & Februari & 1007 & 818 & 303 \\
\hline 6 & Maret & 302 & 1522 & 296 \\
\hline 7 & April & 500 & 1528 & 286 \\
\hline 8 & Mei & 871 & 1742 & 446 \\
\hline 9 & Juni & 805 & 2167 & 219 \\
\hline 10 & Juli & 503 & 2753 & 156 \\
\hline 11 & Agustus & 501 & 3100 & 312 \\
\hline 12 & September & 508 & 3289 & 441 \\
\hline
\end{tabular}

\section{Analisa Proses}

Dalam perhitungan fuzzy logic metode mamdani dibutuhkan beberapa variabel yang menjadi input dan output dari metode perhitungan. Adapun variabel yang terdapat dalam kasus stock meteran prabayar PT.PLN Rayon Indarung adalah angka penjualan, persediaan dan permintaan.

\section{Fuzzyfikasi}

Ada 2 variabel utama untuk input dan 1 variabel output untuk menentukan jumlah angka penjualan. Persediaan input 1 dan permintaan input 2 sebagai output yaitu angka penjualan. Seperti dilihat pada tabel di bawah ini : 
UPI YPTK Jurnal KomTekInfo Vol. 5, No. 1, Juni 2018, Hal. 81-95 ISSN :2356-0010 | eISSN :2502-8758 Copyright@2018 by LPPM UPI YPTK Padang

Semesta Pembicaraan

\begin{tabular}{|l|l|l|}
\hline Fungsi & Nama Variabel & Semesta Pembicaraan \\
\hline \multirow{2}{*}{ Input } & Permintaan & {$[10-1100]$} \\
\cline { 2 - 3 } & Persediaan & {$[0-3350]$} \\
\hline Output & Penjualan & {$[150-500]$} \\
\hline
\end{tabular}

\section{Analisa untuk Variabel Permintaan}

Variabel permintaan mempunyai nilai yang dinyatakan dengan kondisi rendah, sedang dan tinggi. Di mana masing-masing kondisi mempunyai rentang nilai yang telah ditentukan dari data laporan pihak PT. PLN Rayon Indarung. Rentang nilai yang ditetapkan tersebut dari nilai terendah 10 bh sampai nilai tertinggi dari 400 - 1100 bh. Himpunan fuzzy untuk input 1 diperlihatkan pada tabel berikut.

Himpunan Fuzzy Permintaan Untuk Input 1

\begin{tabular}{|l|l|l|l|}
\hline Variabel & Model MF & Variabel Himpunan & Range \\
\hline \multirow{3}{*}{ Permintaan } & Trapmf & Rendah & $10-400$ \\
\cline { 2 - 4 } & Trimf & Sedang & $300-900$ \\
\cline { 2 - 4 } & Trapmf & Tinggi & $500-1100$ \\
\hline
\end{tabular}

Diagram membership fuzzy untuk input permintaan dapat dilihat pada gambar dibawah ini.

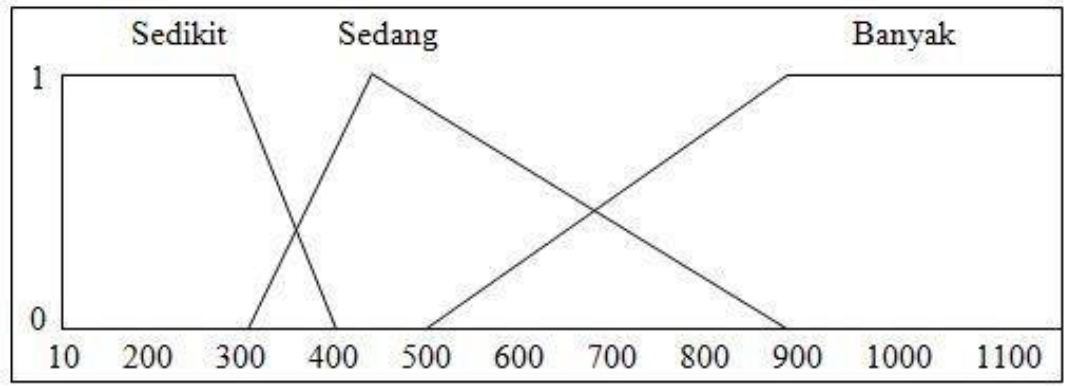

Membership Function Variabel Permintaan

Dari diagram membership fuzzy tersebut dapat dilihat persamaan himpunan fuzzy rendah :

$$
\mu_{r \text { (rendah })=}=\left\{\begin{array}{cc}
1 \quad ; 10 \leq a<300 \\
\frac{400-a}{100} ; 300<a<400 \\
0 \quad ; a \geq 400
\end{array}\right.
$$

Persamaan himpunan fuzzy sedang :

$$
\mu_{s(\text { sedang })=} \begin{cases}\frac{a-300}{100} & ; 300 \leq a \leq 400 \\ \frac{900-a}{500} & ; 400 \leq a \leq 900 \\ 0 & ; a \leq 300 \text { atau } a \geq 900\end{cases}
$$

Persamaan himpunan fuzzy tinggi :

$$
\mu_{t \text { (tinggi })}= \begin{cases}0 & ; a \leq 500 \\ \frac{a-500}{400} ; & 500<a<900 \\ 1 \quad & ; 900 \leq a \leq 1100\end{cases}
$$

\section{Analisa untuk Varibel Persediaan}

Variabel persediaan mempunyai nilai yang dinyatakan dengan kondisi rendah, sedang dan tinggi. Di mana masing-masing kondisi mempunyai rentang nilai yang telah ditentukan dari data laporan pihak PT. PLN Rayon Indarung. Rentang nilai yang ditetapkan tersebut dari nilai terendah 0 bh sampai nilai tertinggi dari 1100 - 3350 bh. Himpunan fuzzy untuk input 2 diperlihatkan pada tabel. 
UPI YPTK Jurnal KomTekInfo Vol. 5, No. 1, Juni 2018, Hal. 81-95 ISSN :2356-0010 | eISSN :2502-8758 Copyright@2018 by LPPM UPI YPTK Padang

Tabel.2 Himpunan Fuzzy Persediaan Untuk Input 2

\begin{tabular}{|c|c|c|c|}
\hline Variabel & Model MF & Variabel Himpunan & Range \\
\hline \multirow{3}{*}{ Persediaan } & Trapmf & Rendah & $0-1100$ \\
\cline { 2 - 4 } & Trimf & Sedang & $350-2200$ \\
\cline { 2 - 4 } & Trapmf & Tinggi & $1400-3350$ \\
\hline
\end{tabular}

Diagram membership fuzzy untuk input persediaan dapat dilihat pada gambar dibawah ini.

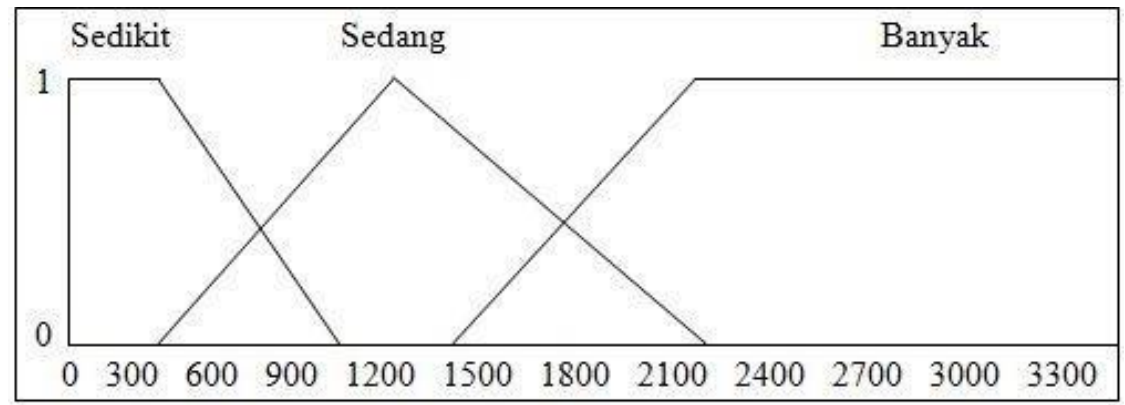

Membership Function Variabel Persediaan

Dari diagram membership fuzzy tersebut dapat dilihat persamaan himpunan fuzzy rendah :

$\mu_{r(\text { rendah })=}$

$$
\left\{\begin{array}{cc}
1 & ; 0 \leq b \leq 350 \\
750 \quad ; 100-b & ; 30<b<1100 \\
1 & ; b \geq 1100
\end{array}\right.
$$

Persamaan himpunan fuzzy sedang :

$$
\mu_{n \text { (sedang) }=} \quad \begin{cases}\frac{b-350}{750} & ; 350 \leq b \leq 1100 \\ \frac{2200-\mathrm{b}}{1100} ; 1100 \leq b \leq 2200 & \\ 0 & ; b \leq 350 \text { atau } b \geq 2200\end{cases}
$$

Persamaan himpunan fuzzy tinggi :

$$
\mu_{t(\text { tinggi })}= \begin{cases}0 & ; b \leq 1400 \\ \frac{b-1400}{800} & ; 1400<b<2200 \\ 1 & ; 2200 \leq a \leq 3350\end{cases}
$$

\section{Analisa untuk Variabel Penjualan}

Variabel penjualan mempunyai nilai yang dinyatakan dengan kondisi rendah, sedang dan tinggi. Di mana masing-masing kondisi mempunyai rentang nilai terendah 150 bh sampai nilai tertinggi 500 bh. Himpunan fuzzy untuk output diperlihatkan pada tabel.

Tabel.3 Himpunan Fuzzy Penjualan untuk Output

\begin{tabular}{|l|l|l|l|}
\hline Nama variabel fuzzy & Model MF & Variabel Himpunan & Range \\
\hline \multirow{3}{*}{ Penjualan } & Trimf & Rendah & $150-280$ \\
\cline { 2 - 4 } & Trimf & Sedang & $260-390$ \\
\cline { 2 - 4 } & Trimf & Tinggi & $370-500$ \\
\hline
\end{tabular}


UPI YPTK Jurnal KomTekInfo Vol. 5, No. 1, Juni 2018, Hal. 81-95 ISSN :2356-0010 | eISSN :2502-8758 Copyright $\bigcirc 2018$ by LPPM UPI YPTK Padang

Diagram membership function untuk output penjualan dapat dilihat pada gambar dibawah ini.

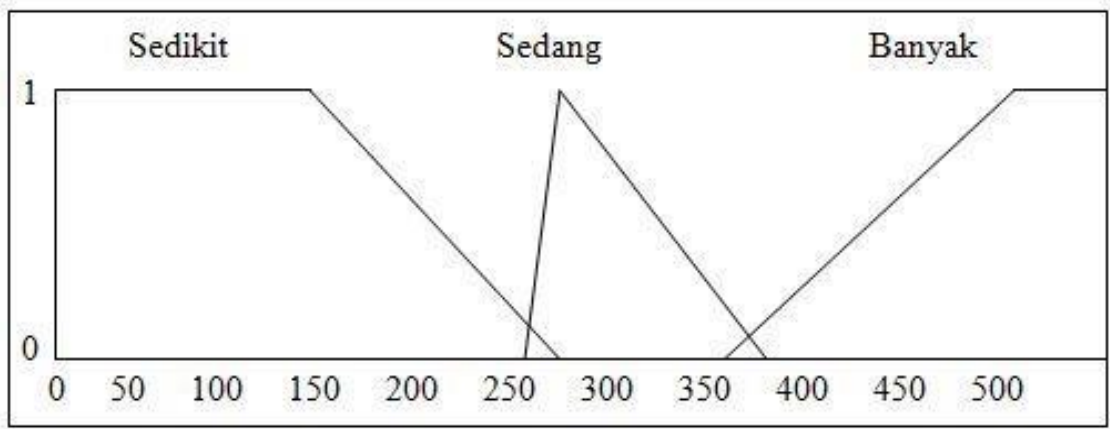

Membership Function Variabel Penjualan.

Dari diagram membership fuzzy tersebut dapat dilihat persamaan himpunan fuzzy ringan :

$$
\mu_{r(\text { rendah })}= \begin{cases}\frac{280-d}{130} & ; 150 \leq c \leq 280 \\ 0 & ; c \leq 280\end{cases}
$$

Persamaan himpunan fuzzy sedang :

$$
\mu_{n(\text { sedang })}=\left\{\begin{array}{c}
\quad \frac{d-260}{20}, 260 \leq c \leq 280 \\
\frac{390-c}{110} ; 280 \leq \mathrm{c} \leq 390 \\
0 \quad ; d<370
\end{array}\right.
$$

Persamaan himpunan fuzzy tinggi :

$$
\mu_{t \text { (tinggi })}= \begin{cases}0 & ; c<260 \text { atau } c>390 \\ \frac{c-370}{130} & ; 370 \leq d \leq 500\end{cases}
$$

\section{Pembentukan Rule}

Dari dua input dan satu output fuzzy tersebut, kita akan menentukan rule-rule. Rule yang diperoleh ada 8 rule yang akan ditetapkan berdasarkan input dan output.

Tabel. 4 Pembentukan Rule

\begin{tabular}{|c|c|c|c|}
\hline \multirow{2}{*}{ No } & \multicolumn{3}{|c|}{ Variabl } \\
\cline { 2 - 4 } & Permintan & Persedian & Penjualn \\
\hline 1 & Rendah & Tinggi & Rendah \\
\hline 2 & Rendah & Sedang & Rendah \\
\hline 3 & Rendah & Rendah & Sedang \\
\hline 4 & Sedang & Tinggi & Sedang \\
\hline 5 & Sedang & Sedang & Tinggi \\
\hline 6 & Sedang & Rendah & Tinggi \\
\hline 7 & Tinggi & Tinggi & Tinggi \\
\hline 8 & Tinggi & Sedang & \\
\hline
\end{tabular}

\section{Pengolahan Data dengan Fuzzy Mamdani}

Pengolahan data menggunakan fuzzy manual bertujuan dapat memberikan penjelasan tentang kerja aplikasi yang digunakan. Adapun prosesnya sebagai berikut:

Contoh :

Penjualan pada bulan oktober

Input: Permintaan $=504$ dan Persediaan $=376$

Adapun langkah - langkah dalam pengolahan data untuk menentukan Penjualan sebagai berikut:

1. Menentukan Himpunan Fuzzy

Variabel Permintaan telah didefinisikan pada tiga himpuan fuzzy, yaitu: rendah, sedang dan tinggi. Permintaan 504 bh termasuk kedalam himpunan fuzzy rendah, sedang dan tinggi maka tingkat keanggotaan sesuai fungsi berikut: 
UPI YPTK Jurnal KomTekInfo Vol. 5, No. 1, Juni 2018, Hal. 81-95 ISSN :2356-0010 | eISSN :2502-8758 Copyright@2018 by LPPM UPI YPTK Padang

a Himpunan Fuzzy Permintaan rendah (504) $=400-504 / 100=0.0$

Nilai 504 tidaktermasuk dalam range Permintaan rendah, maka hasil yang didapat adalah 0,0 .

b. Himpunan Fuzzy Permintaan sedang $(504)=900-504 / 500=0,80$.

Nilai 504 termasuk dalam range Permintaan normal, maka hasil yang didapat adalah 0,80 .

c. Himpunan Fuzzy Permintaan tinggi $(504)=504-400 / 500_{-}=0,20$

Nilai 504 termasuk dalam range Permintaan tinggi, maka hasil yang didapat adalah 0,52.Variabel permintaan telah didefinisikan pada tiga himpuan fuzzy, yaitu: rendah, sedang dan tinggi.

Variabel persediaan telah didefinisikan pada tiga himpuan fuzzy, yaitu: rendah, sedang dan tinggi. Persediaan 376 bh termasuk kedalam himpunan fuzzy rendah maka tingkat keanggotaan sesuai fungsi berikut:

a. Himpunan Fuzzy Persediaan rendah $(376)=1100-376 / 750=0,96$

Nilai 376 termasuk dalam range Persediaan rendah,maka hasil yang didapat adalah 0,96 .

b. Himpunan Fuzzy Persediaan sedang $(376)=2200-376 / 1000=1,82$

Nilai 376 tidak termasuk dalam range Persediaan sedang, maka hasil yang didapat adalah 1,82 .

c. Himpunan Fuzzy Persediaan tinggi $(376)=376-1400 / 1000=0,0$.

Nilai 376 tidak termasuk dalam range Persediaan tinggi, maka hasil yang didapat adalah 0,0.Variabel persediaan telah didefinisikan pada tiga himpuan fuzzy, yaitu: rendah, sedang dan tinggi.

\section{Penalaran ( Inferensi)}

Tahap dari proses perhitungan fuzzy berikutnya adalah tahapan penalaran. Dalam proses penalaran ada 3 hal yang dilakukan yaitu mengaplikasi operator fuzzy, metode implikasi dan komposisi. Dari 8 rule yang ada, rule fuzzy yang akan ditampilkan hanya 4 aturan saja,yaitu (Rule 4), (Rule 5), (Rule 7) dan (Rule 8) sedang yang lainnya dapat dilihat pada tabel 4.6. Proses rule dapat dilihat sebagai berikut

[Rule 4] If (Permintaan is sedang) and (Persediaan is tinggi) then (Penjualan is sedang)

Operator yang digunakan adalah AND, sehingga :

$$
\begin{aligned}
\alpha 4 & =\min (\mu \text { permintaan }[504], \mu \text { persediaan[376] }) \\
& =\min (0,80 ; 0,0) \\
& =0,0
\end{aligned}
$$

[Rule 5] If (Permintaan is sedang) and (Persediaan is sedang) then (Penjualan is sedang)

Operator yang digunakan adalah AND, sehingga :

$$
\begin{aligned}
\alpha 5 & =\min (\mu \text { permintaan }[504], \mu \text { persediaan[376] }) \\
& =\min (0,80 ; 1,82) \\
& =0,80
\end{aligned}
$$

[Rule 7] If (Permintaan is tinggi) and (Persediaan is tinggi) then (Penjualan is tinggi)

Operator yang digunakan adalah AND, sehingga :

$$
\begin{aligned}
\alpha 7 & =\min (\mu \text { permintaan }[504], \mu \text { persediaan[376] }) \\
& =\min (0,20 ; 0,0) \\
& =0,0
\end{aligned}
$$

[Rule 8] If (Permintaan is tinggi) and (Persediaan is sedang) then (Penjualan is tinggi)

Operator yang digunakan adalah AND, sehingga :

$$
\begin{aligned}
\alpha 8 & =\min (\mu \text { permintaan }[504], \mu \text { persediaan[376]) } \\
& =\min (0,20 ; 1,82) \\
& =0,20
\end{aligned}
$$

\section{Defuzzifikasi}

Langkah terakhir dalam proses ini adalah defuzzifikasi atau disebut juga tahap penegasan.Metode yang digunakan adalah metode centroid. Berikut ini mengubah himpunan fuzzy menjadi bilangan real 
UPI YPTK Jurnal KomTekInfo Vol. 5, No. 1, Juni 2018, Hal. 81-95 ISSN :2356-0010 | eISSN :2502-8758

Copyright@2018 by LPPM UPI YPTK Padang

[ Rule 4 ] $\mu$ Penjualan sedang $(x)=0,0$, maka nilai $\mathrm{x}$ adalah ;

Penjualan $($ sedang $)=(x-260) / 20=0,0$

$$
\begin{aligned}
& =(0,80 \times 20)+260 \\
& =260
\end{aligned}
$$

[ Rule 5 ] $\mu$ Penjualan sedang $(x)=0,80$, maka nilai $\mathrm{x}$ adalah ;

Penjualan (sedang) $\quad=(x-260) / 20=0,80$

$$
=(0,80 \times 20)+260
$$$$
=276
$$

[ Rule 7] $\mu$ Penjualan tinggi $(x)=0,0$, maka nilai $\mathrm{x}$ adalah ;

Penjualan (tinggi) $\quad=(x-370) / 220=0,0$

$$
\begin{aligned}
& =(0,0 \times 220)+370 \\
& =370
\end{aligned}
$$

[ Rule 8] Penjualan tinggi $(\mathrm{x})=0,20$, maka nilai $\mathrm{x}$ adalah ;

Penjualan (tinggi) $\quad=(x-370) / 220=0,20$

$$
=(0,20 \times 220)+370
$$$$
=414
$$
adalah:

Maka, dengan menggunakan metode defuzzy weighted average diperoleh nilai angka penjualan

$$
\begin{aligned}
\mathrm{Z}_{1} & =\frac{(0,0 * 260)+(0,80 * 276)+(0,0 * 370)+(0,20 * 414)}{0,0+0,80+0,0+0,20} \\
& =\frac{0+221+0+83}{1} \\
& =304 \\
& =304(\text { Sedang })
\end{aligned}
$$

\section{Analisa Sistem}

Analisa sistem merupakan suatu penguraian dari suatu sistem informasi yang utuh kedalam bagian-bagian komponennya dengan maksud untuk mengidentifikasi dan mengevaluasi permasalahan, kesempatan, hambatan yang terjadi dan kebutuhan yang diharapkan sehingga dapat diusulkan perbaikannya.

\section{Perancangan Use case diagram}

Use case diagram menggambarkan bagaimana proses-proses yang dilakukan oleh aktor terhadap sebuah sistem. Hanya dua aktor yang terlibat dalam sistem ini yaitu administrator dan manajer.

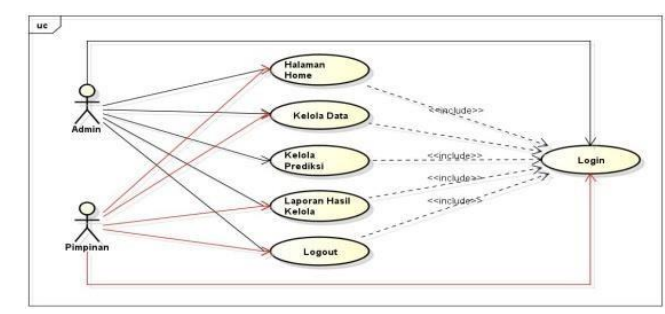

\section{Gambar.2 Usecase Diagram}

\section{Class Diagram}

Class diagram adalah kumpulan objek-objek yang mempunyai struktur umum, relasi umum, dan semantic. Class-class ditentukan dengan memeriksa objek-objek dalam sequence diagram dan collaboration diagram. Sebuah class digambarkan seperti sebuah bujur sangkar dengan tiga bagian ruangan 
UPI YPTK Jurnal KomTekInfo Vol. 5, No. 1, Juni 2018, Hal. 81-95 ISSN :2356-0010 | eISSN :2502-8758 Copyright@2018 by LPPM UPI YPTK Padang

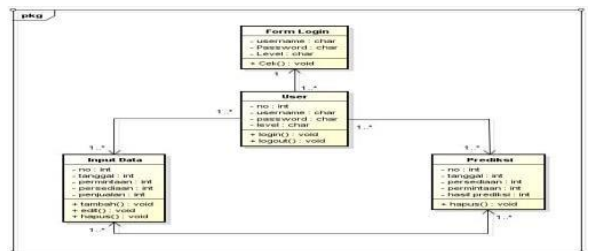

Gambar.3 Class Diagram

\section{Sequence Diagram}

Squence diagram adalah suatu penyajian perilaku yang tersusun sebagai rangkaian langkahlangkah percontohan dari waktu ke waktu. Sequence diagram digunakan untuk menggambarkan arus pekerjaan.

\section{Perancangan Interface}

Adapun dalam perancangan interface ini penulis mendeskripsikan konsep aplikasi yang akan dirancang sebagai acuan atau desain awal pada perancangan aplikasi fuzzy logic dengan metode mamdani

\section{Implementasi}

Implementasi Sistem

Untuk mengoperasikan sistem ini dibutuhkan perangkat keras dan perangkat lunak yang memadai, dalam mengimplementasikan fuzzy logic ini peneliti menggunakan perangkat keras (hardware) dan perangkat lunak (software)

\section{Pengujian Interface}

Login merupakan halaman yang pertama kali ditampilkan ketika mengakes sistem. untuk dapat login maka admin harus memasukkan username dan password yang benar pada form login seperti pada gambar berikut :

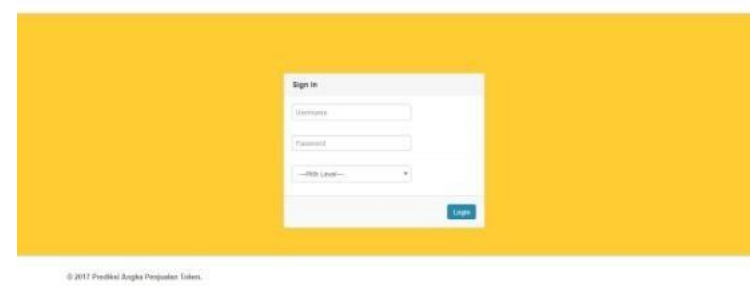

Gambar.4 Halaman Login

Tampilan home merupakan tampilan awal yang menampilkan penjelasan sejarah suatu perusahaan.

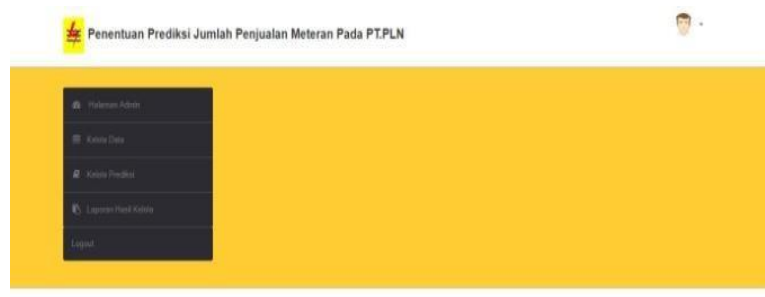

Gambar.5 Halaman Home

Tampilan kelola data merupakan tampilan untuk memperlihatkan data yang sudah diinputkan.

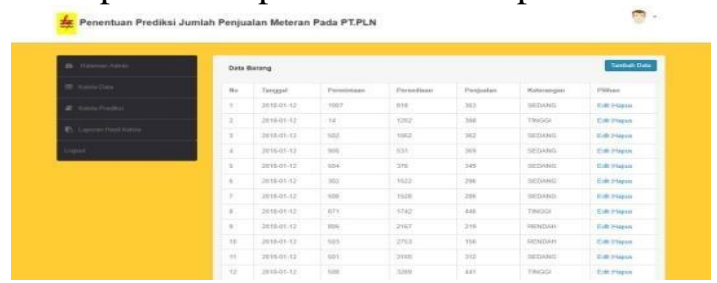

Gambar.6 Tampilan Kelola Data

Tampilan form input data untuk mengimputkan data permintaan, persediaan dan penjualan 
UPI YPTK Jurnal KomTekInfo Vol. 5, No. 1, Juni 2018, Hal. 81-95 ISSN :2356-0010 | eISSN :2502-8758 Copyright@2018 by LPPM UPI YPTK Padang

sebelum diolah menggunakan metode mamdani.

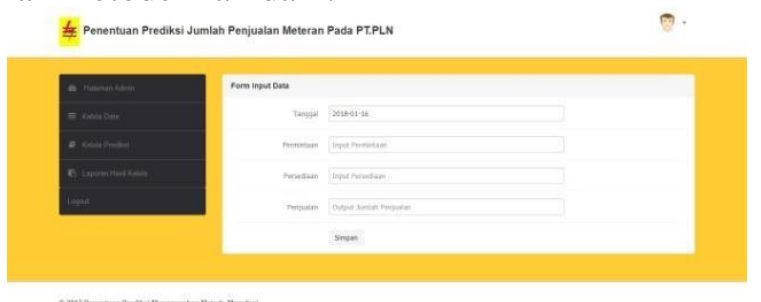

Gambar.7 Tampilan Form Input Data

\section{Tampilan Kelola Prediksi}

Tampilan kelola data merupakan tampilan untuk memperlihatkan data yang sudah melakukan prediksi.

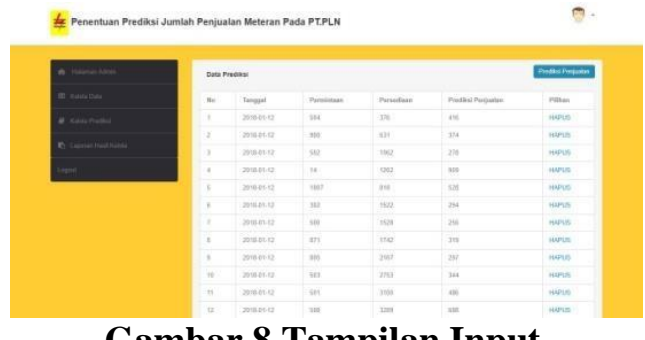

Gambar.8 Tampilan Input

\section{Tampilan Form Input Prediksi}

Tampilan form input prediksi untuk mengimputkan data permintaan, persediaan dan memanggil output penjualan yang sudah kita inputkan sebelumnya sebelum melakukan perhitungan dengan metode mamdani.

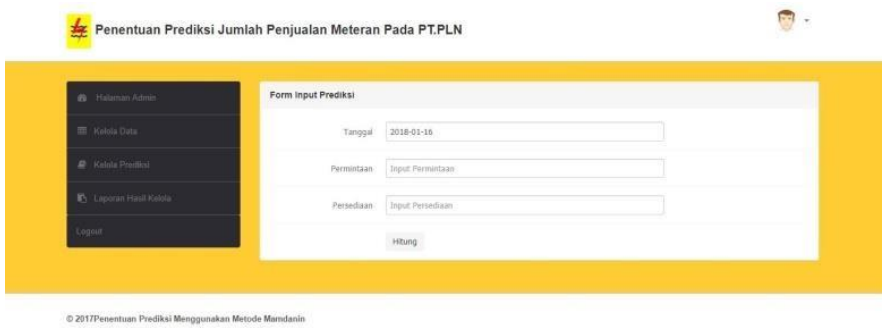

\section{Gambar.9 Tampilan Form Input}

\section{Prediksi Tampilan Logika Perhitungan Fuzzy}

Setelah data prediksi diinputkan, form prediksi akan menampilkan logika perhitungan fuzzy mamdani sebelum kita simpan.

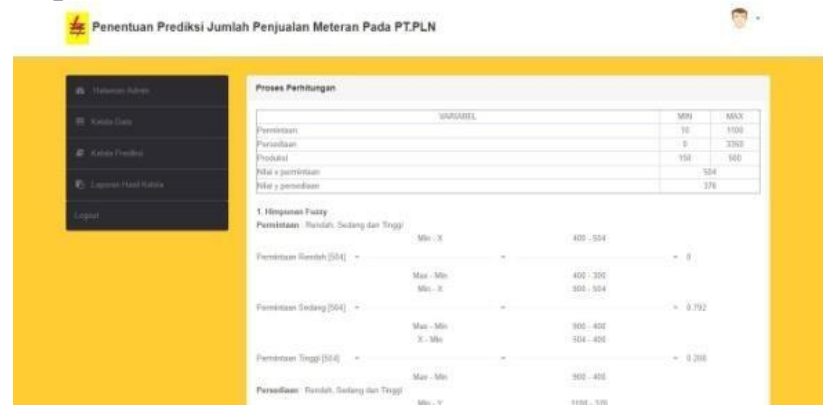

Gambar.10 Tampilan Logika Perhitungan Fuzzy

\section{Tampilan Laporan Hasil Data Prediksi}

Tampilan laporan hasil data prediksi merupakan tampilan untuk memperlihatkan data sebelum dikelola dan yang sudah melakukan prediksi. 
UPI YPTK Jurnal KomTekInfo Vol. 5, No. 1, Juni 2018, Hal. 81-95 ISSN :2356-0010 | eISSN :2502-8758 Copyright@2018 by LPPM UPI YPTK Padang

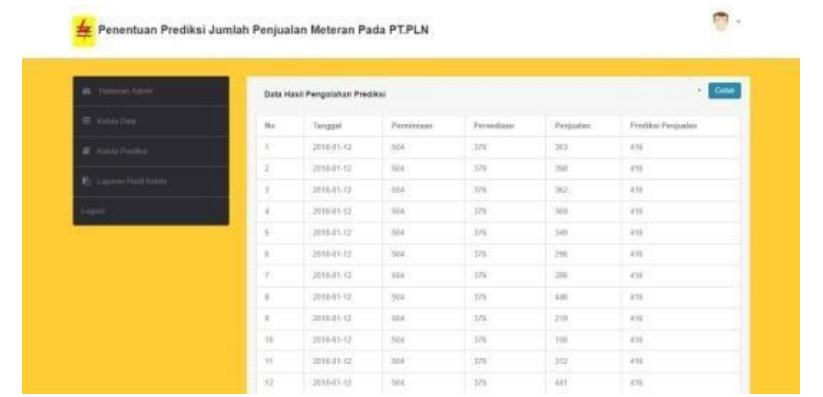

Gambar.11 Tampilan Laporan Hasil Data Prediksi

\section{PENUTUP}

\section{Kesimpulan}

Berdasarkan penelitian yang penulis lakukan pada PT. PLN (Persero) Rayon Indarung Padang mengenai sistem baru yang diterapkan dengan logika fuzzy, maka penulis dapat menarik kesimpulan bahwa metode Fuzzy Mamdani akan bermanfaat dalam pengambilan keputusan.

Atas analisis dan pembahasan yang penulis lakukan maka penulis dapat mengambil kesimpulan sebagai berikut:

1. Dapat menggunakan data primer hasil survei dua program dari listrik pasca bayar dan prabayar untuk mendapatkan jumlah persediaan pada pihak PT. PLN dan jumlah permintaan pada pelanggan.

2. Pihak PT. PLN dapat membatasi meteran pasca bayar dengan menentukan pelanggan yang patut menggunakan meteran listrik pasca bayar atau prabayar dengan melihat beberapa aspek kebutuhan pelanggan.

3. Dapat menentukan stock meteran prabayar (token) berdasarkan jumlah persediaan yang terdapat pada pihak PT. PLN dan banyaknya permintaan pemasanggan dari pelanggan.

\section{Saran}

Dari hasil penelitian ini maka penulis dapat mengumpulkan saran-saran sebagai berikut:

1. Untuk mendapatkan sebuah keputusan yang cukup tinggi tingkat keakuratannya maka dapat digunakan metode Fuzzy Mamdani.

2. Penulis menyarankan agar dapat membandingkan metode pengambilan keputusan dengan menggunakan metode fuzzy logic dengan metode atau teknik yang lain.

3. Program yang dirancang diharapkan dapat dijadikan sebagai bahan dalam pengembangan dan penelitian lebih lanjut sehingga mampu menghasilkan suatu program yang lebih efektif dengan tingkat keakuratan lebih tinggi dari program ini.

\section{DAFTAR PUSTAKA}

[1] A.S., Rosa dan M. Shalahuddin. "Rekayasa Perangkat Lunak Terstruktur Dan Berorientasi Objek". Bandung: Informatika, 2013.

${ }^{[2]}$ Agustin, Ami Hilda dkk. "Penerapan Metode Fuzzy Sugeno Untuk Menentukan Harga Jual Sepeda Motor Bekas”. E-Jurnal Matematika (2016) Vol. 5 (4).

[3] Bahroini, Ahmad dkk. "Prediksi Permintaan Produk Mie Instan Dengan Metode Fuzzy Takagi-Sugeno". Kumpulan Jurnal Ilmu Komputer (2016) Vol. 03 No. 02.

${ }^{[4]}$ Haryanto, Edy Victor dan Fina Nasari. "Penerapan Metode Fuzzy Mamdani Dalam Memprediksi Tingginya Pemakaian Listrik: Studi Kasus Kelurahan ABC”. Seminar Nasional Teknologi Informasi dan Multimedia (2015).

${ }^{[5]}$ Kadir, Abdul. "Belajar Database Menggunakan MySQL”. Yogyakarta: Penerbit Andi, 2008.

${ }^{[6]}$ Kusumadewi, Sri dan Sri Hartati. “Neuro-Fuzzy: Integrasi Sistem Fuzzy \& Jaringan Saraf”. Yogyakarta: Graha Ilmu, 2010.

${ }^{[7]}$ Mandala, Eka Praja Wiyata. "Web Programming Project 1: e.p.w.m. Forum”. Yogyakarta: Penerbit Andi, 2015.

${ }^{[8]}$ Putri, Anggia Dasa dan Effendi. "Fuzzy Logic Untuk Menentukan Lokasi Kuis Terbaik Di Kepri Mall Dengan Menggunakan Metode Sugeno”. Jurnal Edik Informatika (2017) V3.il(49-59).

${ }^{[9]}$ Rahmaddeni. "Penerapan Fuzzy Logic Dalam Menganalisis Tingkat Pendapatan Akhir Konsultan Produk Multi Level Marketing: Studi Kasus PT. Orindo Alam Ayu Cabang Pekanbaru”. Jurnal Sains, Teknologi dan Industri (2014) Vol. 11 No. 2. 
UPI YPTK Jurnal KomTekInfo Vol. 5, No. 1, Juni 2018, Hal. 81-95 ISSN :2356-0010 | eISSN :2502-8758 Copyright@2018 by LPPM UPI YPTK Padang

${ }^{[10]}$ Saleh, Alfa. “Implementasi Metode Fuzzy Mamdani Dalam Memprediksi Tingkat Kebisingan Lalu Lintas”. Seminar Nasional Teknologi Informasi dan Multimedia (2015).

[11] Sasmito, Ginanjar Wiro. "Penerapan Metode Waterfall Pada Desain Sistem Informasi Geografis Industri Kabupaten Tegal”. Jurnal Informatika: Jurnal Pengembangan IT (JPIT) (2017) Vol. 2 No. 1.

${ }^{[12]}$ Sidik, Betha. "Pemrograman Web Dengan PHP 7". Bandung: Informatika, 2017. 